\title{
Doctor-patient Conversation Analysis: A Sociolinguistic Perspective on the Case of COVID-19 in Esfahan, Iran
}

\author{
Jamal Poursamimi \\ Department of English Language and Literature, Arak University, Arak, Iran \\ Malihe Khubroo \\ Department of English Language and Literature, Arak University, Arak, Iran \\ Seyyed Hossein Sanaeifar \\ English Department, Islamic Azad University, Qaemshahr Branch, Qaemshahr, Iran
}

\begin{abstract}
Comprehending the striking role of Conversation Analysis (CA) research in a real context on the one hand, and a substantial part doctors play in doctor-patient conversation in the proceeding stages of receiving medical intensive care as an inherent nature of society on the other hand, provoked the researchers to conduct this research. To achieve this intention, the present study focuses on conversation aspects of doctorpatient talks in unconfirmed cases of COVID-19 in Golpayegan, Esfahan, Iran. This study tries to find out what conversation aspects are more frequently used by Iranian interlocutors in the context of the doctors' office. Three doctor-patient meetings, for this purpose, were audio-recorded, then transcribed. The focus is on both the talk and nonverbal aspects of conversation to be analyzed. After doing the conversation analysis, it was found that turn-taking was the most frequently used conversation aspect. Because this investigation is among the first conversation analysis research which is conducted in the Iranian doctor-patient context in COVID-19 setting, it seems outstanding. In addition, as teaching conversation analysis to students in parallel with other outstanding skills, sub-skills, and language components has great importance, and the analysis method utilized in the current research is conversation analysis, this study sounds prominent.
\end{abstract}

Index Terms - conversation analysis, conversation aspects, doctor-patient meeting, interruption, overlap, pause, turn-taking

\section{INTRODUCTION}

Language is a social institution which is used as a means of communication in everyday life. The importance of language and communication is clear as everyone finds it the easiest way of expressing his/her ideas and wishes. Wardhaugh (1992) believed that conversation is a type of oral communication that lets humans express themselves and ideas in a bidirectional way since it is a social activity involving at least two individuals, a speaker and a hearer, who play interactive roles in transferring and sharing words, ideas and information.

In order to study and analyze communications, Conversation Analysis (CA) was established through the work of Harvey Sacks and his colleagues Emmanuel A. Schegloff and Gail Jefferson by the late 1960s and early 1970s. CA concerns a daily interaction as an integral part of man's life and nature by analyzing which conversation analysts can attempt to understand the patterns in a social life that will be helpful to develop procedural rules governing talks in an interaction.

Conversation as a type of spoken interaction can take place in every situation, from daily classroom conversation to even institutional talks such as courtroom discourse. According to Drew and Heritage (as cited in Wong \& Waring, 2010, p. 4), "CA researchers analyze instances of talk, ranging from a casual conversation between friends, acquaintances, co-workers or strangers to talk in more formal settings such as classroom, doctor-patient consultation [which is the focus of this study], courtroom proceedings, radio talk programs, interviews and so on".

Since there is a dearth of publications in the area of doctor-patient conversation, a doctor's clerk granted the researchers permission to audio record three doctor-patient meetings, without primarily informing the participants of the current study, to investigate the types of conversation aspects found in a doctor's office in Golpayegan, Esfahan, Iran. However, the permission of the participants, the doctor and the patients was sought after the meetings.

In this study, first, a literature review of what has been explicit within the space of conversation analysis was mentioned. Then, the research question was raised. Afterwards, the data collection process and the data analysis procedure were explained. After that, the frequency of conversation aspects in question was brought. At last, the importance of the study, the implications, and the conclusion of the research were mentioned. 


\section{CONVERSATION ANALYSIS}

Conversation analysis has been a locus of pedantic interest for over forty years (Celce-Murcia, Brinton \& Snow, 1991, p. 110). CA began life within the late Nineteen Sixties and early Seventies as a sub discipline of social science (Markee, 2000). CA is based on a social science conceptualization of the essentially social nature of language use in human interaction. According to Bhatia, Flowerdew and Jones (2008), "as the work in CA has developed, it has come to be a truly multi-disciplinary field" (p. 22).

Briefly, CA is a social science field that tries to uncover the systematic properties of serial organization of speech and the social practices also displayed by and embodied in talk-in-interaction (Lazaraton, 2002, p. 29). Talk-in-interaction refers to totally different varieties of speech and their concomitant body language that occurs in mundane life across settings from casual to institutional contexts (Wong \& Waring, 2010). "CA researchers focused on describing the organizational structure of mundane, ordinary conversation" (Markee, 2000, p. 24), which can be outlined as the kind of casual, social speech that habitually happens between acquaintances and friends, either on the telephone or face-to-face. Goffman (1964, p. 65) argued that "talk is socially organized, not merely in terms of who speaks to whom in what language, but as a little system of mutually ratified and ritually governed face-to-face action, a social encounter".

Ethnomethodology evolved a research convention i.e. CA which mainly concentrates on studying how natural conversations in social interactions are organized (also referred to as talk-in- interaction) by means of deeply going through tape recordings and transcriptions. Involved in the communication approaches of meanings and pragmatic functions in ordinary conversations and formally institutional kinds of speech including interviews and court hearings, CA have found out that such topics are an organization of talk, turn-taking sequence, and the procedures of recognizing and repairing problems of communication (Richards \& Schmidt, 2010).

According to Psathas (1995), CA attempts to study the order of social action, significantly those social actions that are situated in a routine interaction, in practices that are discursive, in the speeches and acts of society members and also in varied ways in which CA grew out of developments in ethnomethodology, ordinary language philosophy, and phenomenology. As it progresses to increase its area of studies, it can be applied in some fields such as cognitive science, communication, discourse analysis, sociolinguistics, social psychology, pragmatics as well as "the branch of study out of which it originally emerged and continues to reside i.e., sociology" (Psathas, 1995, p. 3).

The term CA generally describes works that are informed by an extending range of disciplinary approaches, including communication theory, the ethnography of communication, ethnomethodology, interactional sociolinguistics, pragmatics, social psychology, speech act theory, and variation analysis (Schiffrin, 1991). Today, CA is particularly influential in many disciplinary approaches. As Bhatia et al. (2008) believe, CA is a branch of science studying the norms, practices and competences underpinning the social interaction's organization. Despite its name, it pertains to all forms of spoken interaction involving typical conversations between friends and relatives, interacting in medical, educational, public media, and socio-legal contexts, relatively monological interactions addressing lectures or speech, and technically complicated interaction including communications comprised of web-oriented multiparty.

As mentioned before, all instances of talk, ranging from a casual conversation between friends, acquaintances talking in more formal settings such as doctor-patient consultation (Drew \& Heritage as cited in Wong \& Waring, 2010, p. 4) can be analyzed by CA researchers. As Drew \& Heritage (1992) noted, analyzing the structure of talk which is used for constructing institutional contexts such as classroom, courtroom, news, and medical contexts (among others) had increasing interest since the late 1970s.

When researchers started to use CA approach in institutional settings such as classrooms (Mehan, 1979) and courtrooms (Atkinson \& Drew, 1979), in order to investigate how everyday talks are modified so that specialized tasks are accomplished and the visibility of these social contexts is achieved (Gill \& Roberts, 2013), and also to reveal how interlocutors orient themselves to institutional identities (Boden \& Zimmerman, 1991; Drew \& Heritage, 1992), medical CA, in doctor-patient consultation settings, emerged as well. According to Gill and Roberts (2013), "CA studies of medicine are valuable in their own right for their ability in illuminating social arrangements in medical settings and the interactional processes that produce them" (p. 589).

\section{DOCTOR-PATIENT CONVERSATION}

The quality of health care that a patient receives depends on the patient and the health care provider (e.g., a physician) interaction and communication. As Ong, De Haes, Hoos \& Lammes (1995) argued, "communication can be seen as the main ingredient in medical care" (p. 903).

Doctor-patient communication generally refers to a variety of interaction between a patient and a care provider, involving the bedside manner that the provider shows but not confined to it, use of communication verbally and nonverbally by either party, and exchanging and comprehending medical data and advice. Communication plays a prominent role in these medical interactions, and it is shown how this property of the doctor-patient interaction is related to medical outcomes by psychological studies. Likewise, issues relevant to common health care (including patient adherence) are dramatically affected by the communication essence between the patient and the physician (Meadors \& Murray, 2014). 
There are some interaction skills training for younger medical practitioners during their professional education in order to encourage them to behave equally in forms of consultation. It is obvious that 'patient-centeredness' has a positive impact on health outcomes (Pilnick \& Dingwall, 2011). Previously, the patient was considered in a primarily evidence-based and biomedical context by medical practice, but the patient-centered approach was given rise by suggestions for clinical methods which incorporate the personal perspective of the patient. This patient-centered approach focuses on the totality of the patient and how all biological factors, psychological factors, and social factors are associated with physical health (Meadors \& Murray, 2014). Certainly, it seems that the patient-centered approach is both more positive medical outcomes and more effective interactions than the doctor-centered or biomedical alternative (Roter \& Hall, 1992).

Traditionally, doctor-patient interaction is treated by researchers as a site "where doctors' exercise power over patients" (Pilnick \& Dingwall, 2011, p. 1374). In the past decades, the emphasis of medical health care is gradually shifted from the disease to the patient. "Presumably, this has resulted in a more egalitarian relationship in which doctor and patient participate in a balanced way in terms of their relative contribution as well as the content of their interaction" (Van Dulmen, 2002, p. 243). Still, a meeting between a doctor and a patient is a kind of meeting between two extremes. Doctor and patient may have various expectations, language, roles, and perspectives. These differences might result in an unbalanced communication.

Regarding the emphasis on the patient, the interaction with the patient is a very essential issue. In specific environments, patients face problematic issues when doctors, instead of interacting with their patients, focus on reading or writing the medical records. It is suggested that doctor's engaging in studying the medical records instead of interacting with the patient may obfuscate the patient about whether the doctor is listening or not. Having such a point of view, Ruusuvuori (2001, p. 1093) stated:

Paying attention to the coordination and timing of these shifts in orientation may help the doctors to develop more patient-centered ways of interacting with the patient. Furthermore, studying the coordination of verbal and non-verbal aspects in medical interaction may complement the current ideas on the constituents of the ideal model of 'patient-centeredness' in medical interaction.

\section{ASPECTS OF CONVERSATION ANALYSIS}

Conversation analysis, as an approach to study ordinary talks in everyday conversations, includes some aspects such as turn-taking, interruption, pause, overlap. According to Celce-Murcia, et al. (1991), the organization systems that underlie conversations and other forms of spoken language, including overall structural organization such as openings, closings, and transitions, repair (i.e. mechanisms for rectifying problems of hearing and understanding in conversation), sequence structure (the linking of turns to the performance of actions like requesting, greeting, etc.), and turn-taking (the structure and distribution of turns), is of great concern to CA studies.

A fundamental feature of conversational organization is turn-taking because it is turns at talk that implements the actions making up conversations. In the analysis of how turn-taking works, it is focused on two major issues: first, what the primary units of turns are and second, how these units are allocated between speakers (Sacks, Schegloff \& Jefferson, 1974).

The roles of the speaker and listener change in a conversation continuously. "The person who speaks first becomes a listener as soon as the person addressed takes his or her turn in the conversation by beginning to speak". The turn-taking rules may differ from one community to another as well as they do differ from one type of speech event (e.g. a conversation) to another (e.g. an oral test) (Richards \& Schmidt, 2010, p. 613).

As Liddicoat (2007) pointed out, one of the most salient features of conversation is changes of speakers. As a matter of fact, only one person speaks at a time and, with few gaps and little overlaps, transitions from speaker to speaker occur fluidly. It does not mean that gaps and overlaps do not occur. Whenever gaps or overlaps occur, they possess the interactional significance; it can be indicated that something additional is happening. Turn-taking is not the result of an inevitable process; it is rather a socially constructed behavior, i.e., speaker change is a normative process that should be achieved by participants in the conversation.

The major concern of Sacks et al. (1974) in the study of turn-taking organization was how to take into account the complex system by which speakers engage in talk and handle to take turns at talks. They argued that interlocutors speak one at a time, mainly, that speaker change will occur quite smoothly, that overlapped speeches are brief, and that from one turn to the next transitions occur with a little gap and no overlapped speeches. Although, turn transition is accomplished in various ways, but these are done through some systematic features.

This idea is in line with Drew and Heritage's (2006) words who believe turn-taking is a kind of organization in both conversation and discourse where interlocutors speak one by one, i.e., they speak one at a time in alternating turns. Practically, turn-taking involves processes that constructs contributions, responds to previous comments, and transitions to different speakers, and uses various linguistic and non-linguistic cues.

There is another conversation aspect in conversation analysis, which is called overlap. In Liddicoat (2007, p. 82) words, "overlapping talk is often thought of as interruption" but they have different interactional features. "An overlapping talk can be either problematic or unproblematic" (Liddicoat, 2007, p. 82). As small amounts of overlaps are not treated as problematic issue by participants, they do not usually seem to be problematic. However, longer overlaps 
may be problematic; "the term interruption is best reserved for these problematic overlaps" (Liddicoat, 2007, p. 82). Speakers do things through their talks in order to deal with this problem.

Whenever more than one speaker is engaging in a conversation, there may be an interruption or overlapping while more than one party is speaking at the same time. Overlap speech in turn-taking may be problematic for interlocutors. There are four kinds of overlapping: first, terminal overlaps, second, continuers, third, conditional access to the turn, and forth, chordal. Terminal overlaps happen when a speaker thinks the other speaker is about to finish his/her, so he/she begins to speak, therefore creating overlap. Continuers are a way of the hearer to show acknowledgment or understanding of what the speaker is saying. As Schegloff (2000) put it, examples of the continuer's phrases can be $\mathrm{mm}$ $h m$ and/or $u h$ huh. Conditional access to the turn implies that, usually as a collaborative effort, the current speaker invites another one to interject in the conversation or yields their turn. Chordal kind of overlapping consists of some turns that occur non-serially; it means both speakers' turns are occurring simultaneously, for instance, laughter. All above types of overlap are non-competitive overlapping in conversation (Schegloff, 2000).

Regarding other aspects of conversation, it can be said that when there is a break in the stream of talk, it is supposed to be a pause. As Liddicoat (2007) put it, "most speaker changes occur without an appreciable pause after the prior speaker's turn and, in fact, an appreciable pause after a turn may be interpreted as an interactional difficulty or problem" (Liddicoat, 2007, p. 52). In fact, it is important to notice whether pauses belong to a particular speaker or not, i.e., whether pauses occur within a turn or between turns.

During the production of utterances when gaps or hesitations appear, pausing, which is a feature of natural speech, commonly occurs. The commonest kinds of pauses are silent pauses which are silent breaks between words and filled pauses, which are gaps that are filled by expressions such as um, er, $\mathrm{mm}$. People who speak quickly often use less pauses than people who speak slowly. When speaking, people may make pauses up to $50 \%$ of their time of speaking. (Richards \& Schmidt, 2010).

\section{REVIEW OF LITERATURE}

Stiles (1979) describes a taxonomy of verbal response mode which is a system of discourse analysis and can be applied to medical interviews. Eight basic categories which are mutually exclusive and exhaustive, are identified in this taxonomy. This taxonomy has yielded precise descriptions of patient-physician interaction. In addition, particular types of verbal exchanges and utterances that are associated with patients' contentment with their medical interviews have been identified in this taxonomy. A detailed descriptive vocabulary is also provided in this system which may be useful to teach interviewing skills.

Adegbite and Odebunmi (2006) conducted a study in some selected hospitals in South-western Nigeria to describe doctor-patient interactions in English, especially their discourse tact in diagnoses. They used recorded conversations between doctors and patients in those selected hospitals as research data. They analyzed participants' mutual contextual beliefs, speech act patterns, and other pragmatic features from pragmatics of discourse perspective.

Cordella and Benjamins (2009) investigated the spoken discourse between doctors and patients in a Chilean teaching hospital setting. The researchers presented the results, i.e., the use of different voices by the participants and their dynamic interrelations in a clinical setting, in an insightful manner. The illustrative figures as well as the extracted data tried to reveal, as a concept, what a voice means; they attempted to show, in a medical consultation, what the function of the voice is, and how the voice is accomplished in talk as an actual strategy.

Ayeloja (2019) did a study at the University of Ilorin Teaching Hospital (UITH), Ilorin. The study aimed at revealing the specific employed discourse devices for enhancing diagnostic communication at hospital through exploring language use in doctor-patient interactions. The researcher adopted conversation analysis theoretical framework and discourse devices conceptual framework for this study. The researcher made fifty tape recordings of doctor-patient verbal interactions as research data. Out of these fifty tape recordings, twenty-five interactions were purposively selected based on their strategic content. Then the data were transcribed orthographically and by using discourse analysis, and the data were analyzed qualitatively.

Afzaal, Khan, Bhatti \& Shahzadi (2019) conducted a study which aimed at investigating discourse features used between the doctors and the patients in the setting of a hospital. By applying Sinclair and Coulthard's (1975) IRF (Initiation, Response and Follow-up) Model, they analyzed communicative patterns between doctors and patients. Their study "explores how doctors and patients make sense of each other's talk" (Sinclair \& Coulthard, 1975, p. 732). After electronically recording the data, which consisted of 30 audio-recorded conversations between doctors and patients, they were translated into English and "transcribed in terms of Dijk's transcription key with the modification" (Sinclair \& Coulthard, 1975, p. 732). The data were "collected from OPD [Out-Patient Department] of Armed Forces Institute of Cardiology and National Institute of Heart Diseases Rawalpindi, Pakistan" (Sinclair \& Coulthard, 1975, p. 733).

\section{METHODOLOGY}

The use of audio or video recordings of participants' conversations is required for the analysis of talk-in-interaction in order to gain the stupendous complexity of conversational behavior (Markee, 2000). The primary source of data consists of these audio or, preferably, video recordings which are used by conversation analysts (Markee, 2000). To 
collect the required data, the researchers observed 3 doctor-patient meetings in the doctor's office in Golpayegan, Esfahan, Iran. The researchers examined the communication between the doctor and the patients by means of consideration of three audio-recorded medical visit sessions. Each meeting took about 10 to 15 minutes. The researchers used a recorder which was placed between the doctor and patients, of course out of their view to avoid eliciting biased data. An ethical approval was obtained to collect the data used for the study, i.e., the doctor's and the patients' cooperation was granted by themselves. They were informed of their voice being recorded after the meetings for the sake of ethical issues, and they agreed with the researchers. Recorded data was entirely used for the sake of the research purpose, and the information was kept confidential. The theoretical framework adopted for this study is conversational analysis. The three recorded meetings were analyzed, and based on the analysis, conversation aspects were identified. Finally, the representative extracts of the conversation aspects were precisely counted and demonstrated in tables.

\section{RESULTS AND DISCUSSION}

While the researchers were absent in the doctor's office, the doctor-patients' conversations were recorded entirely. Three recorded meetings were analyzed. Then, the researchers identified conversation aspects of doctor-patients' conversations. Two raters carried out the process of identifying and transcribing the conversation aspects (shown as CA in the following tables) of doctor-patients' meetings. The raters identified the conversation aspects separately. The report of the findings is brought in the following tables.

TABLE 1

THE FREQUENCY OF INVESTIGATED CONVERSATION ASPECTS For THE FIRST PATIENT

\begin{tabular}{|c|c|c|c|c|}
\hline $\begin{array}{c}\text { CA } \\
\text { Frequency } \\
\end{array}$ & $\begin{array}{l}\text { Interruption } \\
0\end{array}$ & $\begin{array}{l}\text { Overlap } \\
0\end{array}$ & $\begin{array}{c}\text { Pause } \\
2\end{array}$ & $\begin{array}{l}\text { Turn-taking } \\
17\end{array}$ \\
\hline \multicolumn{5}{|c|}{$\begin{array}{c}\text { TABLE } 2 \\
\text { THE FREQUENCY OF INVESTIGATED CONVERSATION ASPECTS FOR THE SECOND PATIENT }\end{array}$} \\
\hline $\begin{array}{c}\text { CA } \\
\text { Frequency } \\
\end{array}$ & $\begin{array}{l}\text { Interruption } \\
2 \\
\end{array}$ & $\begin{array}{l}\text { Overlap } \\
7\end{array}$ & $\begin{array}{c}\text { Pause } \\
7\end{array}$ & $\begin{array}{l}\text { Turn-taking } \\
19\end{array}$ \\
\hline \multicolumn{5}{|c|}{$\begin{array}{c}\text { TABLE } 3 \\
\text { THE FREQUENCY OF INVESTIGATED CONVERSATION ASPECTS FOR THE THIRD PATIENT }\end{array}$} \\
\hline $\begin{array}{c}\text { CA } \\
\text { Frequency }\end{array}$ & $\begin{array}{c}\text { Interruption } \\
4\end{array}$ & $\begin{array}{c}\text { Overlap } \\
8\end{array}$ & $\begin{array}{c}\text { Pause } \\
1\end{array}$ & $\begin{array}{c}\text { Turn-taking } \\
30\end{array}$ \\
\hline
\end{tabular}

As it is shown in the tables, the most frequent conversation aspect that participants, i.e., the doctor and the patients, followed in the three doctor-patients' meetings were turn-taking, which seems natural in this context. Regarding the results of the current study, the researchers realized that turn-taking is one of the conversation aspects that if applied to the doctor-patient interaction, it provides a good relationship between them since the relationship between the doctor and the patient is more important than the biological treatment. Stiles (1979, p. 263) who expressed that the verbal interaction between a doctor and a patient is a fundamental means of medical treatment and diagnosis, confirms this idea and believes that patients who come to doctors seek a good relationship as more or much than a biological treatment. "They may want to air their troubles or vent their feelings; they may want instructions on how to relieve their suffering; they may want reassurance or information to calm their fears regarding their health". As Stiles (1979) argues, even biological treatment and diagnosis heavily depend on the relationship between a doctor and a patient. Doctors are better to establish a trusting atmosphere to gain complete and accurate information in order to make a diagnosis and to apply interpersonal influences to seek the close co-operation of patients in treatment "including compliance with medication instructions, dietary restrictions, and return appointments" (Stiles 1979, p. 264).

The researchers in the current study observed that after initial conversations, i.e., greetings and replies, the conversation begins with a doctor eliciting information about the patients' illness in which turn-taking occurs regularly. This result of the current study contradicts Adegbite's (1991) research result. Adegbite (1991) expressed that, by dictating the pace of the turn taking, the doctor controls the interaction. According to the result of this study, the doctor interrupted at will and used dominant acts such as accusations, caution, and directives in order to check the patient during the interaction. According to the present study, it is concluded that in the medical system, the patient must have confidence in order to achieve diagnosis and medication successfully. Such confidence is expected to be built around the doctor's care and also other medical personnel.

The analysis of the data of the present study regarding the structure of doctor-patients' interaction yielded a similar result to the findings of Adegbite and Odebunmi (2006) who summarized the overall content structure of the transaction into two parts, first, identifying the problems, their sources and symptoms and second, attempting to find solutions to the problems. "The interaction is dialogical and constituted by a series of turn-taking activities" between the doctors and their patients (Adegbite \& Odebunmi, 2006, p. 506).

Regarding the result of the current study, the opening of the conversation was usually initiated by the doctor in order to either elicit or confirm information. The doctor's opening was also aimed at giving directives to the patients. The doctor-patients' interaction was supposed to have a salutary effect on the patients as it is argued that psychology has become one of the most noteworthy disciplines in health care. The doctor tried to find a solution to the patients' illness 
in a collaborative search with the patients. It is obvious that instances of disagreement and argument between the doctor and the patients would be rare.

It is in line with Adegbite and Odebunmi's (2006, p. 505) claim in which they argued doctors are trained to investigate solutions and find it to all types of patients' sickness. They asserted that "part of the training of medical doctors includes medical ethics, medical history and practice and medical communication with both medical personnel and patients" (Adegbite \& Odebunmi, 2006, p. 506). As they argued, doctors are well-prepared to understand all treatment, prognosis, and diagnosis of patients. The purport of diagnostic interactions between doctor and patient is consultative. While writing down a medical report, i.e., notes on their prescriptions and observations to prescribe a treatment for the patient, the medical doctors engage patients in the conversation with a view in order to diagnose patients' problems as in this study when the doctor and the patient engage in a collaborative conversation to find a solution for the patient's problem. Adegbite and Odebunmi's (2006) findings indicated that doctors give directives to patients and elicit and confirm information. Doctor-initiated spoken exchanges are predominated in doctor-patient interaction. Their findings also indicated that the patients attempt to respond to the doctors' moves appropriately, and they also give information to the doctors. Adegbite and Odebunmi (2006) observed that politeness maxims are exploited and conversation maxims are flouted to enhance a profitable diagnosis in the interaction. They argued that "doctorpatient interaction is only one of the aspects of medical communication that language scholars should pay attention to gain insight into language as an act of social behavior and action, especially with respect to the institution of medicine" (Adegbite \& Odebunmi, 2006, p. 499).

The analysis of Cordella and Benjamins' (2009) research data revealed that "the functions of a doctor voice are to seek information, to assess and review (information) and to align with authority" (Cordella \& Benjamins, 2009, p. 855). It is argued that doctors facilitate patients' storytelling through the fellow human voice with the patient. Also, the doctors create empathy to show attentiveness to the stories of the patients. In addition, doctors ask questions that are unrelated to the patient's health in order to create a friendly atmosphere to reassure the patient. This result is in line with the result of the present study in which the doctor behaved in a kindly manner toward his patients to create a good, calm, and friendly atmosphere.

In the present study, a number of conversation actions such as turn-takings and pauses are performed in doctorpatients' interactions in order to ensure cordiality while in Ayeloja's (2019) study, for ensuring cordiality, rapport expressions that were realized by social questions were deployed. So, in Ayeloja's (2019) study, a number of pragmatic functions are performed by the identified discourse devices. For instance, doctors employed rapport expressions for cordiality, solidarity and open communication while for this purpose in the present study the turn-taking aspect of the conversation was employed by the doctor. Doctors in Ayeloja's (2019) study also employed counselling to guide patients to know how to handle their health very well. Likewise, the doctor investigated in the present study, by his utilized discourse, seems to believe that helping the patients to handle the health problem is more important than prescribing medicines. In both mentioned studies, it was investigated that the doctors initiated the opening of the conversation and patients terminated consultations by closing of the conversations, and in both studies, the patients made use of the answer in order to respond to queries. In the present study, the doctor used an opening conversation aspect to give directives to the patients while in Ayeloja's (2019) study, doctors employed imperatives for giving directives. Totally, Ayeloja (2019) argued that "knowledge of the discourse devices and their pragmatic functions, therefore, is important for a better understanding of diagnostic discourse in the Nigerian context" (Ayeloja, 2019, p. 23).

In their study, Afzaal et al. (2019) concluded that there is a significant difference in language use between the doctors and the patients both in spoken and written forms. They pointed out that in an exchange structure, commonality, familiarity, and solidarity were lacking in the conversation between doctors and patients. This lack of commonality, solidarity and familiarity resulted in misunderstanding of the doctor and patient talk. The result of the present study which shows a strong sense of solidarity between the doctor and the patients, contradicts the result of the study conducted by Afzaal et al. (2019). Since in the current research, the doctor asked several questions of the patients during the physical examination of them applying a turn-taking aspect of conversation to enhance the sense of solidarity between himself and his patients in their communication.

\section{CONCLUSION}

The researchers were motivated to conduct this study because of the dearth of research in the area of medical conversation in the Iranian context in the context of COVID-19 epidemic. Since this study is one of the initiating attempts in conversation analysis in Iranian doctor-patient settings, it can be significant for exploring people discourse in such a context. The area of research is an untouched and new field of study, especially for conversation analysts to try to conduct further research.

It is supposed that the hospitals, clinics, and doctors' offices are places where doctors, nurses, and other personnel provide medical care for sick people. According to Adegbite and Odebunmi (2006), two classes of people are essential in hospitals as institutions where medical care is provided for patients: all medical personnel including the administrative, doctor, intern, medical student, nurse, other medical staff, and paramedic, and patients. As one of the most underlying areas in health care is mental health in general and good conversations between doctors and patients in 
particular, investigating the conversation aspects between doctors and patients should be a fundamental concern these days which motivated the researchers of this study to conduct such a study.

Mentioning the pivotal impact of the current study on both doctor-patient conversations and pedagogical settings, i.e., the discourse aspect of language taught to English language learners, is an important issue. Firstly, since doctor-patient interaction is one of the most momentous aspects of medical communication which should be considered by language researchers, and this study is a CA case of doctor-patient analysis, thus, the significance of the present study is definitely highlighted. As it is claimed that assisting patients in handling a health problem situation is of great importance, this study is supposed to help doctors to understand this critical subject matter. In addition, because language is regarded as an act of social behavior, the current study that investigates the conversation aspects between interlocutors in society generally and between doctors and patients specially sounds an influential research.

Secondly, nurturing English language learners by teachers in order to foster their language competence in all aspects of language skills and components, especially the discourse aspect, is of great significance. So, to fulfill this aim, it is required to carefully consider conversation aspects of language, i.e., language beyond sentences level, as one of those important components being taught in the process of teaching English to language learners. Unless the conversation aspect of the language is taught, language learners will not be competently competent at being target language speakers. Since the utilized method in the current study was one of conversations analytic aspects, it is expected that this study helps English language teachers to teach the conversation aspect of language more suitably in English Language Teaching (ELT) contexts.

\section{ACKNOWLEDGEMENTS}

We wish to acknowledge the doctor's clerk, who wished not to be named, in Golpayegan, Esfahan, Iran, who was of great aid to us in order to collect the data. In addition, we would like to thank the participants of this study, the doctor and the patients who asked us to keep them unknown. When we informed them that we had audio-recorded their meetings, they granted us permission to use their talks as our data.

\section{REFERENCES}

[1] Adegbite, W. (1991). Some features of language use in Yoruba traditional medicine. (Unpublished Doctoral Thesis). University of Ibadan, Ibadan, Nigeria.

[2] Adegbite, W., \& Odebunmi, A. (2006). Discourse tact in doctor-patient interactions in English: An analysis of diagnosis in medical communication in Nigeria. Nordic Journal of African Studies, 15(4), 499-519.

[3] Afzaal, M., Khan, M., Bhatti, A-G., \& Shahzadi, A. (2019). Discourse and corpus based analysis of doctor-patient conversation in the context of Pakistani hospitals. European Online Journal of Natural and Social Sciences, 8(4), 732-752.

[4] Atkinson, J. M., \& Drew, P. (1979). Order in court: The organization of verbal interaction in judicial settings. London: Macmillan.

[5] Ayeloja, A. K. (2019). Discourse devices and pragmatic functions in doctor-patient verbal interactions at university of Ilorin teaching hospital, Ilorin, Nigeria. International Journal on Studies in English Language and Literature, 7(2), 22-36.

[6] Bhatia, V. K., Flowerdew, J., \& Jones, R. H. (2008). Advances in discourse studies. London: Routledge.

[7] Boden, D., \& Zimmerman, D. H. (1991). An introduction to structure in action. In D. Boden \& D. H. Zimmerman (Eds.), Talk and social structure: Studies in ethnomethodology and conversation analysis (pp. 3-21). Berkeley: University of California Press.

[8] Celce-Murcia, M., Brinton, D. M., \& Snow, M. A. (1991). Teaching English as a second or foreign language. The United States: National geographic learning.

[9] Cordella, M., \& Benjamins, J. (2009). The dynamic consultation: A discourse analytical study of doctor-patient communication. Journal of Pragmatics, 41, 854-856.

[10] Drew, P., \& Heritage, J. (1992). An introduction to analyzing talk at work. In D. Paul \& J. Heritage (Eds.), Talk at work: Interaction in institutional settings (pp. 3-65). Cambridge: Cambridge University Press.

[11] Drew, P., \& Heritage, J. (2006). Conversation analysis. London: SAGE Publications Ltd.

[12] Gill, V. T., \& Roberts, F. (2013). Conversation analysis in medicine. In J. Sidnell \& T. Stivers (Eds.), The handbook of conversation analysis (pp. 575-592). UK: Blackwell Publishing.

[13] Goffman, E. (1964). The neglected situation. Berkeley: University of California.

[14] Lazaraton, A. (2002). A qualitative approach to the validation of oral language tests. UK: Cambridge University Press.

[15] Liddicoat, A. J. (2007) An introduction to conversation analysis. London: Athenaeum Press.

[16] Markee, N. (2000). Conversation analysis second language acquisition research. London: Lawrence Erlbaum Associates.

[17] Meadors, J., D., \& Murray, C. B. (2014). Measuring nonverbal bias through body language responses to stereotypes. Journal of Nonverbal Behavior, 38(2), 209-229.

[18] Mehan, H. (1979). Learning lessons: Social organization in the classroom. The United States: Cambridge, Harvard University Press.

[19] Ong, L. M., De Haes, H., Hoos, A. M., \& Lammes, F. B. (1995). Doctor-patient communication: A review of the literature. Social Science \& Medicine, 40(7), 903-918.

[20] Pilnick, A., \& Dingwall, R. (2011). On the remarkable persistence of asymmetry in doctor/patient interaction: A critical review. Social Science \& Medicine, 72, 1374-1382.

[21] Psathas, G. (1995). Conversation analysis: The study of talk in interaction. London: Sage publication.

[22] Richards, J. C., \& Schmidt, R. (2010). Dictionary of language teaching and applied linguistics. UK: Pearson ESL. 
[23] Roter, D. L. \& Hall, J. A. (1992). Doctors talking with patients/Patients talking with doctors: Improving communication in medical visits. The United States: Auburn House, Westport, CT.

[24] Ruusuvuori, J. (2001). Looking means listening: Coordinating displays of engagement in doctor-patient interaction. Social Science and Medicine, 52, 1093-1108.

[25] Sacks, H., Schegloff, E. A., \& Jefferson, G. (1974). A simplest systematics for the organization of turn-taking for conversation. Language, 50(4), 696-735.

[26] Schenkein, J. (1978). Studies in the organization of conversational interaction. New York: Academic Press.

[27] Schegloff, E. A. (2000). Overlapping talk and the organization of turn-taking for conversation. Language in Society, 29(1), 163.

[28] Schiffrin, D. (1991). Conversation analysis. Annual Review of Applied Linguistics, 11, 3-16.

[29] Sinclair, J. M., \& Coulthard, M. (1975). Towards an analysis of discourse: The English used by teachers and pupils. London: Oxford University Press.

[30] Stiles, W. B. (1979). Discourse analysis and the doctor-patient relationship. International Journal of Psychiatry in Medicine, 9(4), 263-274.

[31] Van Dulmen. A. M. (2002). Different perspectives of doctor and patient in communication. International Congress Series, $1241,243-248$

[32] Wardhaugh, R. (1992). An introduction to sociolinguistics. Oxford: Blackwell.

[33] Wong, J., \& Waring, H. Z. (2010). Conversation analysis and second language pedagogy: A guide for ESL/EFL teachers. UK: Routledge publication.

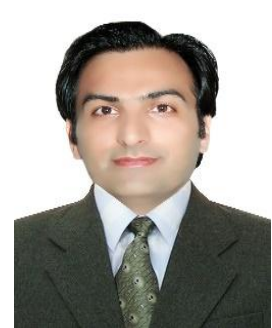

Jamal Poursamimi has BA of TEFL at Bojnord State University, Iran and MA of TEFL at Arak State University, Iran. His research interests are applied linguistics, intercultural communication, sociolinguistics, and critical discourse analysis.

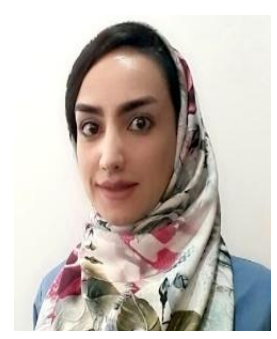

Malihe Khubroo has BA of English translation. She has MA of TEFL at Arak University, Iran. Her research interests are sociolinguistics, discourse analysis, and critical discourse analysis.

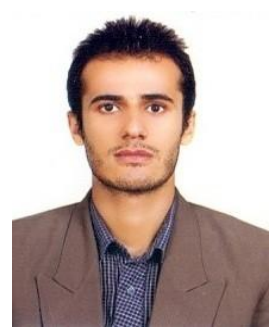

Seyyed Hossein Sanaeifar has MA of TEFL. He is Ph.D. candidate of TEFL at Islamic Azad University, Qaemshahr, Iran. He is a full-time English teacher of the Ministry of Education in Iran. He has been teaching English for about 8 years in Iranian public schools and private language institutes. He published some articles and presented some articles at national and international conferences in Iran. His areas of interest are teacher education, reading comprehension, vocabulary and idiom learning, and language assessment and testing. 